ORIGINAL ARTICLE

\title{
Relation between policies and work related assault: Minnesota Nurses' Study
}

\author{
N M Nachreiner, S G Gerberich, P M McGovern, T R Church, H E Hansen, M S Geisser, A D Ryan
}

Occup Environ Med 2005;62:675-681. doi: 10.1136/oem.2004.014134

See end of article for authors' affiliations .....................

Correspondence to: Dr N Nachreiner, Division of Environmental 'Health Sciences, School of Public Health, University of Minnesota, Mayo Mail Code 807, 420 Delaware Street SE, Minneapolis, Minnesota 55455, USA; nachr001@umn.edu

Accepted 18 March 2005
Aims: To assess the relation between violence prevention policies and work related assault. Methods: From Phase 1 of the Minnesota Nurses' Study, a population based survey of 6300 Minnesota nurses (response 79\%), 13.2\% reported experiencing work related physical assault in the past year. In Phase 2, a case-control study, 1900 nurses (response 75\%) were questioned about exposures relevant to violence, including eight work related violence prevention policy items. A comprehensive causal model served as a basis for survey design, analyses, and interpretation. Sensitivity analyses were conducted for potential exposure misclassification and the presence of an unmeasured confounder.

Results: Results of multiple regression analyses, controlling for appropriate factors, indicated that the odds of physical assault decreased for having a zero tolerance policy $(O R=0.5,95 \% \mathrm{Cl} 0.4$ to 0.8 ) and having policies regarding types of prohibited violent behaviours $(\mathrm{OR}=0.5,95 \% \mathrm{Cl} 0.3$ to 0.9$)$. Analyses adjusted for non-response and non-selection resulted in wider confidence intervals, but no substantial change in effect estimates.

Conclusions: It appears that some work related violence policies may be protective for the population of Minnesota nurses.
O ver 600 work related homicides occurred in the USA during 2002 alone, and it is estimated that approximately 1.7 million non-fatal acts of violence occurred at work annually between 1993 and 1999. ${ }^{12}$ Workers in certain occupations, including nursing, are at increased risk of non-fatal work related assault. ${ }^{3-8}$ Primarily, descriptive studies have been used to identify the prevalence of violence focused on particular facilities, units, or sub-groups of nurses; however, it is difficult to compare these data when definitions of violence, study populations, and study periods differed. Estimates range from $87 \%$ of staff being assaulted five times per year ${ }^{9}$ to $57 \%$ of staff per year, ${ }^{10}$ with numerous studies reporting percentages in between.

Currently, there is no mandate, only recommendations, from the federal Occupational Safety and Health Administration (OSHA) regarding work related violence prevention measures. In 1996, OSHA published Guidelines for preventing workplace violence for health care and social service workers. ${ }^{11}$ These guidelines are advisory in nature, neither standards nor regulations. The recommendations state that employers should create "a clear policy of zero-tolerance for workplace violence, verbal and non-verbal threats, and related actions". ${ }^{11}$ Few data exist to support recommendations from many researchers and OSHA to implement policies, ${ }^{11-21}$ therefore, evaluation of these recommendations is necessary.

It is unclear how many organisations have policies regarding work related violence. ${ }^{22}{ }^{23}$ However, simply having a violence prevention policy does not ensure a safe work environment. ${ }^{24} 25$ What is included within a violence prevention policy varies by institution. Some authors have recommended a "zero-tolerance policy", ${ }^{11}$ 26-30 while others cautioned against its use ${ }^{31} 32$ with the argument that zero tolerance policies are inflexible, and that legal problems are created if an institution does not consider a penalty appropriate for the particular offence. However, even definitions of "zero tolerance" may vary. Wilkinson ${ }^{33}$ defined zero tolerance to mean that violence at work was unacceptable, but not that specific predetermined consequences were necessary.
There are very few studies reporting on the impact of policy. Runyan and colleagues ${ }^{34}$ critically reviewed published literature on administrative and behavioural interventions regarding work related violence and found that, overall, the research designs were weak and results were inconclusive. Among the studies, the types of violence prevention policies varied greatly. Researchers have reported primarily positive policy effects such as: increased awareness of risk situations for violence, avoiding dangerous situations, and improvements in dealing with aggressive patients at worksites where an intervention programme was introduced; ${ }^{35}$ decreased number of violent incidents after policy implementation; ${ }^{36} 37$ and decreased assault rates after programme implementation. ${ }^{38}$ However, only one study used a multivariate, casecontrol approach, and reported a protective effect of policies. ${ }^{6}$ The others have been primarily descriptive, with no control for other exposures.

Based on this limited literature, it is clear that there is a need to evaluate further the impact of work related violence prevention policies on physical assault. While descriptive studies may suggest potential risk factors, it is not possible to estimate the specific risk without a well designed analytic effort with rigorous measurement of relevant exposures. Without such an effort, the development of appropriate and efficacious prevention and control strategies cannot be initiated. The purpose of this study was to assess the relation between violence prevention policies and work related physical assault.

\section{METHODS}

This study was based on data collected for the Risk Factors for Violence Among Nurses (RFVAN) ${ }^{39}$ study, designed to estimate the extent of, and to identify specific risk factors for work related violence. Prior to implementation of this effort, approval was received from the University of Minnesota Institutional Review Board, Human Subjects Committee.

\section{Target population}

The target for this study was the population of Minnesota nurses, licensed as of 1 October 1998. At that time, there were 
an estimated 79128 licensed nurses in the state (57388 registered nurses; 21740 licensed practical nurses), according to the State of Minnesota Mailing List Service. ${ }^{40}$ Besides name, licence type, and address, the state database included birth date, gender, and year of first licensure.

\section{Data collection}

The RFVAN study consisted of two phases: a comprehensive study (Phase 1), and a nested case-control study (Phase 2). Following a pilot study of 220 nurses, a specially designed survey was sent to a random sample $(n=6300)$ from the population of Minnesota nurses (Phase 1). This survey enabled identification of those who worked as nurses in Minnesota in the past year and, among them, those who experienced work related violence during that time. Work related violence was defined as the intentional use of physical force or emotional abuse, against an employee, that resulted in physical or emotional injury and consequences. This included physical assault, threat, sexual harassment, and verbal abuse. The current study focuses specifically on the outcome of physical assault, defined as when one was slapped, kicked, pushed, choked, grabbed, sexually assaulted, or otherwise subjected to physical contact intended to injure or harm.

A nested case-control design was utilised in Phase 2 to examine the relation between exposures and work related physical assault. Through the case-control survey, data were obtained on various factors, including personal exposures (for example, patient contact hours), environmental exposures (for example, work related violence prevention policies, type of department), and characteristics of others in the environment. Cases were surveyed about their exposures for the month prior to and during the assault. Unmatched controls were randomly selected to describe exposures from all months worked by nurses during the study period (the 12 months prior to the date the nurse completed the survey), but prior to any physical assaults for each nurse. This sampling method was to ensure that the distribution of sampled months represented the distribution of months worked.

For each phase, as many as four follow up mailings were implemented to optimise the response rate. Data relevant to the policy implications from the case-control study were the primary focus of this study.

\section{Case and control definitions}

Cases $(n=475)$ were defined as those nurses who reported at least one episode of physical violence in the previous 12 months. If multiple events of physical violence were reported by the same nurse, the participant was asked questions regarding the most remote event. Unmatched controls $(n=1425)$ were selected in a 3:1 ratio to cases from

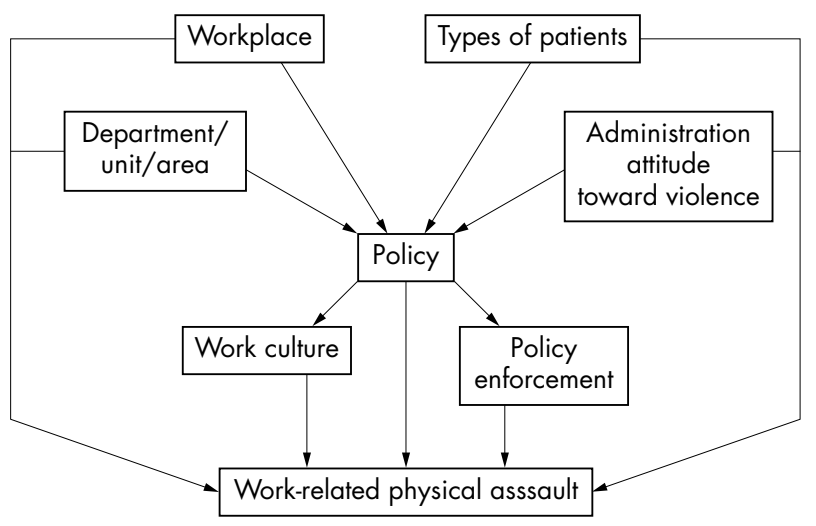

Figure 1 Work related assault: impact of policy causal model. among those who reported no physical assault. Cases were also eligible to be chosen as controls during the months prior to their first assault.

\section{Policy definitions}

Nurses were asked about eight different policy components: "Prior to (specific month), did your facility/institution/agency have a written policy on violence that addressed any of the following: (a) 'zero tolerance' for violence, that is, violence was not tolerated at any level; (b) types of violent behaviours (physical assault, threat, sexual harassment, or verbal abuse) that were prohibited; (c) consequences for those who used violence at work; (d) how to report if someone sexually harassed, threatened, or verbally abused you; (e) how to report if someone physically assaulted you; (f) assurance that reporting of violent incidents would be kept confidential; ( $\mathrm{g}$ ) requirements for violence prevention training of staff members; and (h) requirements for flagging of charts or other signals to staff members regarding patients/clients with repeated violent behaviour?" Response options included yes, no, and unsure. They were then asked the degree to which policy components were enforced.

\section{Analysis}

A comprehensive diagram representing causal relationships was used to depict variables included in the data collection instruments; a directed acyclic graph derived from the diagram also served as a basis for analyses, selection of confounders for multiple logistic regression, and for interpretation of results. ${ }^{41}$ A portion of this causal diagram is shown in fig l. Univariate analyses, using SAS version 8.02, were performed first to describe the characteristics of individual exposures. Once the directed acyclic graph, based on the causal model was established, it was used to determine which variables should be included as possible confounders when studying the exposures of interest: work related violence policy components. These methods are based on those presented by Greenland and colleagues, ${ }^{41}$ and Maldonado and Greenland, ${ }^{42}$ and as illustrated by Hernan and colleagues. ${ }^{43}$ The variables in the sufficient set of confounders were the minimum required to block all "backdoor pathways" (potentially confounding relationships) from the exposure of interest (policy) to the outcome (work related physical assault). To avoid a potential source of bias in the analysis, variables that were located in the causal pathway between the exposure of interest and the outcome were not included in the model. Multiple logistic regression ${ }^{44}$ was used to investigate the relation between specific exposures and the occurrence of work related violence.

Potential response bias was controlled by inversely weighting responses by probabilities of response estimated as a function of characteristics available from the licensing database (age, gender, licence type, home address (metropolitan area versus non-metropolitan area))..$^{45}$ To control for unknown eligibility among non-respondents, each nonrespondent was down-weighted by the estimated probability of ineligibility among nurses with the same characteristics. ${ }^{46}$ To represent variability from all sources, confidence intervals for regression coefficients were calculated by using the bootstrap method. ${ }^{47}$

\section{Employer validation sub-study}

A sub-study was conducted to validate nurse responses regarding specific work characteristics, including written work related violence prevention policies, by comparing responses between nurses and employers. For this sub-study, letters were sent to a random sample of nurses ( 135 cases and 135 controls), requesting the names of their employing institutions. A subset of the questions pertinent to policies, to 
Table 1 Work related assault: impact of policy participant characteristics

\begin{tabular}{|c|c|c|c|c|}
\hline & \multicolumn{2}{|c|}{ Cases $(n=310)$} & \multicolumn{2}{|c|}{ Controls $(n=946)$} \\
\hline & $\mathrm{n}$ & $\%$ & $\mathrm{n}$ & $\%$ \\
\hline \multicolumn{5}{|l|}{ Practice type } \\
\hline RN & 213 & 68.7 & 701 & 74.1 \\
\hline LPN & 97 & 31.3 & 245 & 25.9 \\
\hline \multicolumn{5}{|l|}{ Gender } \\
\hline Female & 293 & 94.5 & 910 & 96.2 \\
\hline Male & 17 & 5.5 & 36 & 3.8 \\
\hline \multicolumn{5}{|l|}{ Age } \\
\hline$<30$ & 22 & 7.1 & 54 & 5.7 \\
\hline 30 to $<40$ & 60 & 19.4 & 134 & 14.2 \\
\hline 40 to $<50$ & 121 & 39.0 & 372 & 39.3 \\
\hline 50 to $<60$ & 79 & 25.5 & 288 & 30.4 \\
\hline 60 or older & 28 & 9.0 & 98 & 10.4 \\
\hline \multicolumn{5}{|l|}{ Nursing education } \\
\hline Diploma & 120 & 38.7 & 361 & 38.2 \\
\hline Associate degree & 118 & 38.0 & 259 & 27.4 \\
\hline Bachelor's degree & 66 & 21.3 & 253 & 26.7 \\
\hline Master's degree or higher & 4 & 1.3 & 59 & 6.2 \\
\hline Missing & 2 & 0.7 & 14 & 1.5 \\
\hline \multicolumn{5}{|l|}{ Primary patient population } \\
\hline Geriatric & 144 & 46.5 & 206 & 21.8 \\
\hline Adult & 110 & 35.5 & 416 & 44.0 \\
\hline Split time & 43 & 13.9 & 191 & 20.2 \\
\hline Neonatal/paediatric/adolescent & 13 & 4.2 & 128 & 13.5 \\
\hline Missing (refused) & 0 & 0.0 & $4(1)$ & $0.4(0.1)$ \\
\hline \multicolumn{5}{|l|}{ Primary professional activity } \\
\hline Provided patient care & 210 & 67.7 & 588 & 62.2 \\
\hline Supervised patient care & 49 & 15.8 & 72 & 7.6 \\
\hline Other & 51 & 16.5 & 285 & 30.1 \\
\hline Missing & 0 & 0.0 & 1 & 0.1 \\
\hline \multicolumn{5}{|l|}{ Type of facility } \\
\hline $\begin{array}{l}\text { Nursing home/long term care/ } \\
\text { rehabilitation facility }\end{array}$ & 143 & 46.1 & 160 & 16.9 \\
\hline Hospital inpatient & 131 & 42.3 & 384 & 40.6 \\
\hline Hospital outpatient/non-hospital outpatient & 11 & 3.5 & 83 & 8.8 \\
\hline Clinic/healthcare provider office & 9 & 2.9 & 119 & 12.6 \\
\hline Other & 16 & 5.2 & 199 & 21.0 \\
\hline Missing & 0 & 0.0 & 1 & 0.1 \\
\hline \multicolumn{5}{|l|}{ Department/unit/area } \\
\hline Long term/assisted care & 123 & 39.7 & 145 & 15.3 \\
\hline Medical/surgical/ob gyn & 71 & 22.9 & 267 & 28.2 \\
\hline Psychiatric/behavioural & 34 & 11.0 & 57 & 6.0 \\
\hline Intensive care unit & 27 & 8.7 & 65 & 6.9 \\
\hline Emergency & 12 & 3.9 & 24 & 2.5 \\
\hline Other & 43 & 14.0 & 386 & 40.8 \\
\hline Missing (refused) & 0 & 0.0 & $1(1)$ & $0.1(0.1)$ \\
\hline
\end{tabular}

which the nurses had already responded through the casecontrol survey, was subsequently posed to the employers without identification of the nurse employee study participants.

\section{RESULTS}

Of the 6300 nurses randomly selected for Phase 1, 79\% responded; $80 \%$ of respondents worked in nursing positions in the previous 12 months, and $13.2 \%$ indicated they experienced work related physical assault in the past year. Phase 2, the nested case-control study, included 1900 nurses (overall response $=75 \%$; response for full surveys $=67 \%$ ). Because patients perpetrated nearly all of the reported physical violence, the analyses presented here focused only on patient perpetrated violence (cases $=310$; controls $=946$ ).

Characteristics of the case-control participants are presented in table 1. Cases and controls were predominately registered nurses, female, and 40-59 years of age. Most frequently, the highest nursing degree was a diploma for both cases and controls. Cases most frequently reported working in a nursing home or long term care facility, while controls worked primarily in a hospital inpatient facility. Cases also worked most frequently with a primarily geriatric population, while controls worked with non-geriatric adults. The primary professional activity for both cases and controls was most often reported as providing patient care; most cases worked primarily on long term or assisted care units, while controls worked on medical or surgical units.

Respondents reported institutional written policies that, among others, addressed zero tolerance for violence and prohibited types of violent behaviours (table 2). The proportions of nurses who reported being unsure of whether or not policies existed ranged from $10 \%$ to $33 \%$ for cases and $15 \%$ to $32 \%$ for controls. When nurses were asked to what degree these policies were enforced, they most frequently stated "unsure". However, a greater proportion of the controls than cases perceived policies to be "always enforced" (20\% of controls compared with $15 \%$ of cases).

Zero tolerance policies were most frequently reported by nurses working in outpatient and "other" facilities, such as schools, insurance, industry, and others. Prohibited behaviour policies were most frequently reported in inpatient hospitals, outpatient facilities, and "other" facilities. Policies regarding consequences for those using violence were most frequently reported in long term care and "other" facilities, as were policies for reporting non-physical violence, and assurance that reporting would be kept confidential. Policies on how to report physical assault were most frequently 
Table 2 Work related assault: impact of policy types of policy components reported

\begin{tabular}{|c|c|c|c|c|}
\hline & Cases $(n=310)$ & & Controls $(n=946$ ) & \\
\hline Policy component & $\mathbf{n}$ & $\%$ & $\mathbf{n}$ & $\%$ \\
\hline \multicolumn{5}{|c|}{ Zero tolerance policy } \\
\hline Yes & 116 & 37.4 & 498 & 52.6 \\
\hline No & 90 & 29.0 & 141 & 14.9 \\
\hline Unsure & 102 & 32.9 & 305 & 32.2 \\
\hline Missing (refused) & $1(1)$ & $0.3(0.3)$ & 2 & 0.2 \\
\hline
\end{tabular}

$\begin{array}{lcccc}\text { Types of violent behaviours that were prohibited (physical assault, threat, sexual harassment, or verbal abuse) } \\ \text { Yes } & 204 & 65.8 & 690 & 72.9 \\ \text { No } & 53 & 17.1 & 80 & 8.5 \\ \text { Unsure } & 61 & 16.5 & 174 & 18.4 \\ \text { Missing (refused) } & 1(1) & 0.3(0.3) & 2 & 0.2\end{array}$

Consequences for those who were violent at work

$\begin{array}{lccrr}\text { Consequences for those who were violent at work } & & & 58 & 62.1 \\ \text { Yes } & 195 & 62.9 & 90 & 9.5 \\ \text { No } & 37 & 11.9 & 964 \\ \text { Unsure } & 75 & 24.2 & 264 & 0.9 \\ \text { Missing (refused) } & 2(1) & 0.6(0.3) & 2 & 0.2\end{array}$

$\begin{array}{lcccr}\text { How to report if someone sexually harassed, threatened, or verbally abused you } & \\ \text { Yes } & 252 & 81.3 & 741 & 78.3 \\ \text { No } & 24 & 7.7 & 66 & 7.0 \\ \text { Unsure } & 32 & 10.3 & 137 & 14.5 \\ \text { Missing (refused) } & 1(1) & 0.3(0.3) & 2 & 0.2\end{array}$

How to report if someone physically assaulted you

$\begin{array}{lcrrr}\text { How to report if someone physically assaulted you } & & & \\ \text { Yes } & 251 & 81.0 & 713 & 75.4 \\ \text { No } & 26 & 8.4 & 70 & 7.4 \\ \text { Unsure } & 31 & 10.0 & 161 & 17.0 \\ \text { Missing (refused) } & 1(1) & 0.3(0.3) & 2 & 0.2\end{array}$

Assurance that reporting of violent incidents would be kept confidential

$\begin{array}{lccrr}\text { Yes } & 168 & 54.2 & 553 & 58.5 \\ \text { No } & 53 & 17.1 & 122 & 12.9 \\ \text { Unsure } & 87 & 28.1 & 269 & 28.4 \\ \text { Missing (refused) } & 1(1) & 0.3(0.3) & 2 & 0.2\end{array}$

Requirements for violence prevention training of staff members

$\begin{array}{lllll}\text { Yes } & 118 & 38.1 & 349 & 36.9\end{array}$

$\begin{array}{lllll}\text { No } & 122 & 39.4 & 360 & 38.1\end{array}$

$\begin{array}{lllll}\text { Unsure } & 68 & 21.9 & 235 & 24.8\end{array}$

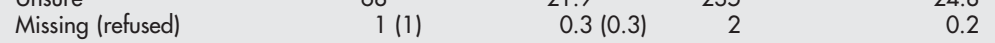

Requirements for flagging of charts or other signals to staff members regarding patients/clients with repeated violent behaviour?

\begin{tabular}{lrrrr} 
Yes & 68 & 21.9 & 205 & 21.7 \\
No & 203 & 65.5 & 452 & 47.8 \\
Unsure & 37 & 11.9 & 287 & 30.3 \\
Missing (refused) & $1(1)$ & $0.3(0.3)$ & 2 & 0.2 \\
\hline
\end{tabular}

reported at long term care and inpatient facilities. Inpatient and outpatient facilities were most frequently reported as having violence prevention training required by policy. Policies regarding flagging charts of violent patients were most frequently reported by those working in long term care facilities.

When stratified by facility type, some policies had significance values of $p<0.05$ when comparing cases and controls, indicating a potentially protective effect of policies. These included the following: zero tolerance policies $(\mathrm{p}<0.01)$, prohibited behaviour policies $(\mathrm{p}<0.02)$, how to report physical assault $(\mathrm{p}<0.01)$, and policies regarding flagging charts at inpatient hospitals $(\mathrm{p}<0.01)$; policies regarding flagging charts at long term care facilities $(\mathrm{p}=0.01)$; zero tolerance policies in outpatient facilities $(p<0.01)$; and assurance of confidentiality in reporting $(\mathrm{p}=0.03)$ and policies on prohibited violent behaviours $(\mathrm{p}<0.01)$ at clinic/healthcare provider offices.

Analyses at the univariate and multivariate levels are shown in table 3. At the univariate level, presence of a zero tolerance policy and policies on prohibited types of behaviours were associated with decreased odds of physical assault. Policies on confidentiality of reporting and flagging of charts of patients with repeated violent behaviour appeared suggestive as protective factors. Based on the comprehensive causal model, the multivariate model (Model 2) adjusted for numerous factors, and again, found zero tolerance policies and policies regarding types of prohibited violent behaviours as protective against assault. However, as shown in Model 3, after adjusting for nonresponse and non-selection of controls, this effect appeared to decrease for both types of policies. 
Table 3 Work related assault: impact of policy logistic regression models

\begin{tabular}{|c|c|c|c|c|c|c|}
\hline \multirow[b]{2}{*}{ Policy component } & \multicolumn{2}{|c|}{ Model 1} & \multicolumn{2}{|c|}{ Model 2} & \multicolumn{2}{|c|}{ Model 3} \\
\hline & OR & $95 \% \mathrm{Cl}$ & OR & $95 \% \mathrm{Cl}$ & OR & $95 \% \mathrm{Cl}$ \\
\hline Zero tolerance & 0.37 & 0.26 to 0.51 & 0.54 & 0.35 to 0.84 & 0.70 & 0.38 to 1.51 \\
\hline Types of prohibited behaviours & 0.45 & 0.31 to 0.65 & 0.54 & 0.33 to 0.90 & 0.56 & 0.32 to 1.43 \\
\hline Confidentiality in reporting & 0.70 & 0.49 to 1.01 & 0.83 & 0.50 to 1.38 & 1.05 & 0.54 to 2.76 \\
\hline Flagging charts & 0.74 & 0.54 to 1.02 & 0.76 & 0.50 to 1.14 & 0.66 & 0.39 to 1.30 \\
\hline Consequences for using violence at work & 0.81 & 0.53 to 1.22 & 0.97 & 0.56 to 1.71 & 1.201 & 0.50 to 2.94 \\
\hline How to report non-physical violence & 0.94 & 0.57 to 1.52 & 1.01 & 0.53 to 1.92 & 1.70 & 0.57 to 4.53 \\
\hline How to report physical violence & 0.95 & 0.59 to 1.52 & 0.70 & 0.36 to 1.34 & 0.82 & 0.35 to 3.02 \\
\hline Required training policies & 1.00 & 0.74 to 1.34 & 0.93 & 0.63 to 1.37 & 1.11 & 0.62 to 1.93 \\
\hline
\end{tabular}

Model 1: Univariate.

Model 2: Multivariate: adjusted for: Workplace [type of facility (Q1), ownership of facility (Q2), location of facility (Q3), total beds at facility (Q4)], Administration attitude [administration's expectation of violence (Q24A), administration's corrective measures against violence (Q24B)], Department/unit/area (Q8), and Types of patients [age of population (Q5), race of patients (Q12A), patient gender (Q12B), patient mental status (13B), average length of patient stay (Q15)]. Model 3: Adjusted and weighted multivariate: adjusted for all variables in Model 2, and also non-response and non-selection.

In addition to the descriptive and multivariate analyses, additional analyses were conducted regarding validity and bias. For the employer sub-study, $49 \%$ (cases $=63$; controls $=69$ ) of the nurses provided the name and address of their employers. Of the 64 employers who responded to this sub-study, and for which there were data reported by the nurse, the percentage agreement (employer and nurse either both answered "yes" or both answered "no") regarding written violence prevention policies varied from $34 \%$ agreement about zero tolerance policies and requirements for training of staff members to $75 \%$ agreement about policies on how to report work related non-physical violence (table 4). Those completing the employer survey also indicated being unsure of policy existence in some instances, which varied from $2 \%$ for reporting non-physical violence to $16 \%$ regarding a policy requiring violence prevention training for staff members. $\chi^{2}$ analyses revealed no important differences between cases and controls when compared with employers' responses.

\section{DISCUSSION}

While violence prevention policies are often recommended to address work related violence, ${ }^{12-21}$ no clear evidence of the efficacy of such policies has been presented. This study was unique in that it enabled identification of the potential effect of violence policies on work related assault in the population of Minnesota nurses.

At the univariate level, all types of policies resulted in decreased risks; two of these (zero tolerance and types of prohibited behaviours) had 95\% confidence intervals excluding 1 . These results are in agreement with those reported by Lee and colleagues. ${ }^{6}$ Through the use of a comprehensive causal model, ${ }^{41}$ multivariate logistic models were constructed to evaluate the impact of policy on work related physical assault. After controlling for relevant variables, zero tolerance policies and policies regarding types of prohibited behaviours again emerged as being important. These findings are similar to conclusions suggested by others. ${ }^{11}{ }^{26-30}$ Additional multivariate logistic regression models were completed for each policy type, and weighted for non-response and nonselection. ${ }^{46}$ Although four policy types remained suggestive of being protective, none were important at this level of analyses.

Eight components of violence prevention policies were studied in this research effort. While a sizable proportion of nurses reported being unsure whether or not policies existed (cases, 10-33\%; controls, 15-32\%), other studies have reported even higher percentages $(>50 \%)$ for this uncertainty. ${ }^{24}{ }^{25}$ This limits the ability to evaluate the impact of policies, and raises questions about the effectiveness of organisational communication of policies and procedures. Also in this study, it was not possible to differentiate the enforcement of each type of policy, only the overall enforcement of all types of violence prevention policies. This may dilute the effect that can be estimated from policy enforcement. However, this study did enable estimation of the policy prevalence and overall enforcement of violence prevention policies, data that are currently unavailable in the literature.

In addition to the descriptive, univariate, and multivariate analyses, additional analyses were conducted regarding validity of the study results. The employer sub-study revealed that, among four of the seven components of policies that were assessed, the percentage agreement between the nurse and the employer, regarding the presence of the policy, was $50 \%$ or greater; two types of policies (how to report physical and non-physical violence) had greater than $70 \%$ agreement. Some disagreement between employer and nurse responses may be related to the role of the person completing the employer survey, which varied greatly: for example, consultant physician; security manager; shift supervisor; administrator; chief executive officer; employees in these positions may have very different levels of knowledge regarding institutional policies.

Table 4 Work related assault: impact of policy employer sub-study policy existence agreement between nurse and employer

\begin{tabular}{|c|c|c|c|}
\hline Type of written policy component & $\begin{array}{l}\text { Case match } \\
\text { ( } n=36 \text { nurses) }\end{array}$ & $\begin{array}{l}\text { Control match } \\
\text { ( } n=28 \text { nurses) }\end{array}$ & $\begin{array}{l}\text { Total } \\
\text { ( } n=64 \text { nurses) }\end{array}$ \\
\hline How to report if someone sexually harassed, threatened, or verbally abused you & $75 \%$ & $75 \%$ & $75 \%$ \\
\hline How to report if someone physically assaulted you & $75 \%$ & $71 \%$ & $73 \%$ \\
\hline Consequences for those who used violence at work & $56 \%$ & $64 \%$ & $59 \%$ \\
\hline $\begin{array}{l}\text { Types of violent behaviours that were prohibited (physical assault, threat, sexual } \\
\text { harassment, or verbal abuse) }\end{array}$ & $56 \%$ & $68 \%$ & $61 \%$ \\
\hline Assurance that reporting of violent incidents would be kept confidential & $39 \%$ & $54 \%$ & $45 \%$ \\
\hline Requirements for violence prevention training of staff members & $31 \%$ & $39 \%$ & $34 \%$ \\
\hline Zero tolerance policy & $28 \%$ & $43 \%$ & $34 \%$ \\
\hline
\end{tabular}




\section{Main messages}

- Work related violence is a significant problem for the population of Minnesota nurses.

- It appears that certain types of policies, specifically zero tolerance policies, and those addressing prohibited types of behaviours, may be protective for this population.

- Many nurses reported being "unsure" of policy existence; therefore, this study is only the first step in understanding the impact of policies on work related violence. Future research would benefit from physical review of work policies, or a study design in which policy existence is known.

The employer sub-study did not appear to be a gold standard for comparison with nurses' responses. Even those completing the employer survey were unsure of some policies' existence. Essentially, the overall study focused on the nurses' perceptions of policies-that is, whether or not the policies actually existed; the employer sub-study compared the nurses' perceptions that written policies existed with the perception of the existence of these policies by the person completing the employer survey. Future studies would ideally include a validation measure comparing nurses' perceptions to a physical review of policies obtained from employers to estimate the degree to which perception may vary from fact.

Organisational culture may have a significant impact on behaviours, regardless of the existence of policies. If a nurse interprets the employer's attitude as having a low tolerance to violence, behaviours may be adjusted accordingly; the opposite is also true-having a zero tolerance policy without management commitment may indicate little about the true impact of policies. Policies cannot stand alone; a strong commitment by management and administration must support the policies. ${ }^{11}$ Lord $^{24}$ found that some employees reported little change in work related violence, even if the employee followed the employer's policy. From the current $^{\text {effort, }}{ }^{24}$ it was reported that over $51 \%$ of the victims of work related violence felt administration did not respond to the incident; according to $53 \%$ of the victims, nothing was done to resolve the situation, and 57\% reported that nothing was done to prevent the incident from happening again.

It is possible that cases may provide better exposure information (differential recall), because they have an event to which exposures can be related; this may vary with controls, who are recalling exposures during a particular month, without having a specific reference event. Sensitivity analyses were conducted to estimate the effect of an unmeasured confounder and exposure misclassification on two types of policies: zero tolerance and types of prohibited violent behaviours policies. In most cases, even after adjusting for a strong unmeasured confounder, both types of policies remained protective, except when paired with extreme differences in the prevalence of the strong unmeasured confounder, where the odds of violence were slightly increased. Similarly, when assessing the effect of exposure misclassification, both types of policies continued to appear protective, except for the rare instance with extreme misclassification error when assessing the impact of zero tolerance policies. Exposure misclassification and/or an unmeasured confounder would have to be extreme to result in changes in the interpretation of the data.

\section{Policy implications}

- The presence of policies, alone, cannot protect workers from violence, as many employees are unsure of policy existence.

- Following a better understanding of the impact of violence prevention policies, and specific risk factors for violence, policies on violence and work methods may be implemented to decrease the incidence of work related violence.

\section{Conclusions}

Work related violence prevention policies are often recommended as part of a comprehensive approach to address occupational violence; however, empirical literature to support these recommendations has been lacking. Certain types of violence prevention policies, specifically zero tolerance policies and policies that address types of prohibited violent behaviours, appear protective in this population of Minnesota nurses. Work related violence is a serious problem, and this study is an important first step in determining the impact of violence prevention policies.

\section{ACKNOWLEDGEMENTS}

Support for this effort was provided, in part, by the National Institute for Occupational Safety and Health, Centers for Disease Control and Prevention, Department of Health and Human Services (R03 OH07373); and the Regional Injury Prevention Research Center and Center for Violence Prevention and Control, Division of Environmental Health Sciences, School of Public Health, University of Minnesota, Minneapolis, Minnesota. The Risk Factors for Violence Against Nurses (RFVAN) study was also supported, in part, by the National Institute for Occupational Safety and Health, Centers for Disease Control and Prevention, Department of Health and Human Services (R01 OH03438). Collaborating organisations included: Minnesota Hospital and Health Care Partnership; Minnesota Nurses' Association; and Minnesota Licensed Practical Nurses' Association.

The authors appreciate the important contributions of Gavin Watt to the design and implementation of the RFVAN study.

\section{Authors' affiliations}

N M Nachreiner, S G Gerberich, P M McGovern, T R Church,

M S Geisser, A D Ryan, Center for Violence Prevention and Control, Regional Injury Prevention Research Center, and Occupational Injury Prevention Research Training Program, Division of Environmental Health Sciences, School of Public Health, University of Minnesota, Minneapolis, MN, USA

H E Hansen, School of Nursing, University of Minnesota, Minneapolis, MN, USA

Funding: Support for this effort was provided, in part, by the National Institute for Occupational Safety and Health (RO3 OH07373 and RO1 $\mathrm{OH} 3438$ ) and the Regional Injury Prevention Research Center and Center for Violence Prevention and Control, Division of Environmental Health Sciences, School of Public Health, University of Minnesota, Minneapolis, Minnesota

Competing interests: none declared

Portions of this paper were presented at the American Public Health Association Conference, Philadelphia, Pennsylvania, November 2002 (Best Paper Award, Student Paper Competition), the Minnesota Health Services Research Conference, Minneapolis, Minnesota, March 2003, and the National Occupational Injury Research Symposium, Pittsburgh, Pennsylvania, October 2003

\section{REFERENCES}

1 US Department of Labor. National census of fatal occupational injuries in 2002. USDOL 03-488. Bureau of Labor Statistics, 2003.

2 Duhart DT. National crime victimization survey: workplace violence 19931999. Bureau of Justice Statistics Report, 2001. 
3 Arnetz JE, Arnetz BB, Soderman E. Violence toward health care workers: prevalence and incidence at a large regional hospital in Sweden. AAOHN 1998;46:107-14.

4 Baxter E, Hafner RJ, Holme G. Assaults by patients: the experience and attitudes of psychiatric hospital nurses. Aust N Z J Psychiatry 1992;26:567-73

5 Carter R. High risk of violence against nurses. Nursing Management 1999/ 2000;6(8):5.

6 Lee SS, Gerberich SG, Waller LA, et al. A case-control study of work-related assault injuries among nurses. Epidemiology 1999;10:685-91.

7 Mahoney BS. The extent, nature, and response to victimization of emergency nurses in Pennsylvania. J Emerg Nurs 1991;17:282-91.

8 US Department of Health and Human Services. Violence in the workplace: risk factors and prevention strategies. DHHS (NIOSH) Publication No. 96-100, 1996.

9 Anon. ENA survey examines facets of workplace violence. American Nurse 1995: 14.

10 Fernandes CMB, Bouthillette F, Raboud JM, et al. Violence in the emergency department: a survey of health care workers. Can Med Assoc J 1999;161:1245-8.

11 Occupational Safety and Health Administration. OSHA 3148. Guidelines for preventing workplace violence for health care and social service workers. Washington, DC: US Department of Labor, Occupational Safety and Health Administration, 1996

12 Baron SA. Organizational factors in workplace violence. Occup Med 1996; 11:335-48.

13 Department of Justice. National Victim Assistance Academy. Chapter 22, Section 5. Workplace violence, 2000. Available at: www.ojp.usoj.gov:80/ ovc/assist/ nvaa2000/academy/chap22-5htm.Accessed 29 March, 2001

14 Eisele GR, Watkins JP, Matthews KO. Workplace violence at government sites. Am J Ind Med 1998;33:485-92.

15 Fitzgerald S, Dienemann J, Codorette MF. Domestic violence in the workplace. AAOHN 1998:46:345-53.

16 Lawless P. Fear and violence in workplace. Minneapolis, MN: Northwestern National Life Insurance Company, 1993.

17 Liss GM, McCaskell L. Violence in the workplace. Can Med Assoc J 1994:151:1243-6.

18 Simonowitz JA. Violence in health care: a strategic approach. Nurse Practitioner Forum 1995;6:120-9.

19 Simonowitz JA, Rigdon JE, Mannings J. Workplace violence: prevention efforts by the occupational health nurse. AAOHN 1997;45:305-15.

20 Trape M. Workplace violence: Occupational Safety and Health Administration guidelines for workers in health care and social services. Conn Med 1998;62:333-6.

21 Yassi A, Tate R, Cooper J, et al. Causes of staff abuse in health care facilities. AAOHN 1998:46:484-91.

22 Bush DF, O'Shea PG. Workplace violence: comparative use of prevention practices and policies. In: VandenBos GR, Bulatao EQ, eds. Violence on the job: identifying risks and developing solutions. Washington, DC: American Psychological Association, 1996:283-97.

23 Lavoie FW, Carter GL, Danzl DF, et al. Emergency department violence in United States teaching hospitals. Ann Emerg Med 1988;17:1227-33.

24 Lord VB. The implementation of workplace violence policy in state government. Violence and Victims 2001;16:185-202.

25 Williams MF. Violence and sexual harassment: impact on registered nurses in the workplace. AAOHN 1996;44:73-7.
26 Cabral R. Policies for developing workplace violence prevention strategies. Occup Med 1996;1 1:303-14.

27 Duda RA. Workplace domestic violence: intervention through program and policy development. AAOHN 1997:45:619-24.

28 Felton JS. Violence prevention at the health care site. Occup Med 1997; 12:701-15

29 Smith-Pittman MH, McKoy YD. Workplace violence in healthcare environments. Nursing Forum 1999:34(3):5-13.

30 Umiker W. Workplace violence: the responsibility of employers and supervisors. Health Care Supervisor 1997; 16(1):29-41.

31 Merchant JA, Lundell JA. Workplace violence intervention research workshop, April 5-7, 2000, Washington, DC. Am J Prev Med 2001;20:135-40.

32 US Office of Personnel Management, Office of Workforce Relations. Dealing with workplace violence: a guide for agency planners. Publication OWR-09, 1998.

33 Wilkinson CW. Violence at work: a business perspective. Am J Prev Med 2001;20:155-60.

34 Runyan CW, Zakocs RC, Zwerling C. Administrative and behavioral interventions for workplace violence prevention. Am J Prev Med 2000;18(4S): 1 16-27.

35 Arnetz JE, Arnetz BB. Implementation and evaluation of a practical intervention programme for dealing with violence towards health care workers. J Adv Nurs 2000;31:668-80.

36 Drummond KJ, Sparr LF, Gordon GH. Hospital violence reduction among high-risk patients. JAMA 1989:261:2531-4.

37 Hunter ME, Love CC. Total quality management and the reduction of inpatient violence and costs in a forensic state hospital. Psychiatr Serv 1996;7:751-4.

38 Flannery RB, Hanson MA, Penk WE, et al. Replicated declines in assault rates after implementation of the Assaulted Staff Action Program. Psychiatr Serv 1998:49:241-3.

39 Gerberich SG, Church TR, McGovern PM, et al. A study of risk factors for violence among nurses, R01 OH03438.Final Technical Report, Centers for Disease Control and Prevention, National Institute for Occupational Safety and Health, 2002.

40 State of Minnesota Mailing List Service. St Paul, MN, 1998

41 Greenland S, Pearl J, Robins J. Causal diagrams for epidemiologic research. Epidemiology 1999; 10:37-48.

42 Maldonado G, Greenland S. Estimating causal effects. Int J Epidemiol 2002;31:422-9.

43 Hernan MA, Hernandez-Diaz S, Werler MM, et al. Causal knowledge as a prerequisite for confounding evaluation: an application to birth defects epidemiology. Am J Epidemiol 2002;155:176-84.

44 Hosmer DW, Lemeshow S. Applied logistic regression. Wiley Series in Probability and Statistics: Texts and References Section. New York: Wiley, 2000.

45 Horvitz DG, Thompson DJ. A generalization of sampling without replacement from a finite universe. Am Stat Assoc J 1952;47:663-85.

46 Mongin SJ. Adjustment for nonresponse in the Minnesota Nurses Study, Health Studies Research Report. Available at: wwwl.umn.edu/eoh/ NewFiles/resreports.html. Division of Environmental and Occupational Health, University of Minnesota, Minneapolis, 2001. Accessed 7 January 2002.

47 Efron B, Tibshirani RJ. An introduction to the bootstrap. In: Cox DR, Hinckley DV, Reid N, Rubin DB, Silverman BW, eds. Monographs on statistics and applied probability. Vol. 57. New York: Chapman and Hall, 1993. 